\title{
Integration of Fuzzy AHP and Fuzzy GTMA for Location Selection of Gas Pressure Reducing Stations: A Case Study
}

\author{
Ahmad Jafarnejad Chaghooshi \\ Professor, Department of Management, University of Tehran, Tehran, Iran \\ Hossein Safari \\ Assistant Professor, Department of Management, University of Tehran, Tehran, Iran \\ Mohammad Reza Fathi (Corresponding author) \\ M.S. Candidate of Industrial Management, University of Tehran, Iran \\ E-mail: reza.fathi@ut.ac.ir
}

Received: May 1, 2012

doi:10.5296/jmr.v4i3.1751
Accepted: June 4, 2012 Published: July 1, 2012

URL: http://dx.doi.org/10.5296/jmr.v4i3.1751

\begin{abstract}
Location selection is a multi-criteria decision problem and has a strategic importance for many companies. In this study, an integrated approach which employs Fuzzy AHP and Fuzzy GTMA is proposed for location selection of Gas pressure reducing stations. The Fuzzy AHP is usedto analyze the structure of location selection problem and to determine weights of the criteria, and Fuzzy GTMA method is used to obtain final ranking. A numerical example demonstrates the application of the proposed method. We apply the integrated approach in a real case to demonstrate the application of the proposed method.
\end{abstract}

Keywords: Graph theory and matrix approach (GTMA), Fuzzy set, Location selection, Analytic Hierarchy Process 


\section{Introduction}

Facility location selection is the determination of a geographic site for a firm's operations (Ertuğrul et al, 2008). The facility location decision involves organizations seeking to locate, relocate or expand their operations (Ertuğrul et al, 2008). The facility location decision process encompasses the identification, analysis, evaluation and selection among alternatives (Yang and Lee, 1997). Selecting a plant location is a very important decision for firms because they are costly and difficult to reverse, and they entail a long term commitment. And also location decisions have an impact on operating costs and revenues. For instance, a poor choice of location might result in excessive transportation costs, a shortage of qualified labor, lost of competitive advantage, inadequate supplies of raw materials, or some similar condition that would be detrimental to operations (Stevenson, 1993). The conventional approaches for facility location problems like locational cost volume analysis, factor rating, and center of gravity method (Stevenson, 1993) tend to be less effective in dealing with the imprecise or vague nature of the linguistic assessment (Kahraman et al, 2003). In real life, the evaluation data of plant location suitability for various subjective criteria and the weights of the criteria are usually expressed in linguistic terms. And also, to efficiently resolve the ambiguity frequently arising in available information and do more justice to the essential fuzziness in human judgment and preference, the fuzzy set theory has been used to establish an ill defined multiple criteria decision-making problems (Liang, 1999). In this paper, Fuzzy AHP-Fuzzy GTMA integrated approach for location selection will be introduced and the implementation process will be explained with a real case. We shall use the FAHP method to analyze the structure of location selection problem and determine the weights of criteria and use FGTMAmethod for final ranking. This paper is divided into five sections. In section "Introduction", the studied problem is introduced. Section "Principles of Fuzzy AHP and Fuzzy GTMA" briefly describes the proposed methodology. In section "Proposed FAHP-FGTMA integrated approach", proposed FAHP-FGTMA integrated approach for location selection of Gas stations is presented and the stages of the proposed approach and steps are determined in detail. The application of proposed method is explained in section "The application of proposed methods". In section "Conclusions and future research", conclusions and future research areas are discussed.

\section{Principles of Fuzzy AHP and Fuzzy GTMA methods}

Before explaining about fuzzy AHP method, it has been described fuzzy sets and fuzzy numbers as follow:

\subsection{Fuzzy sets and fuzzy numbers}

Fuzzy set theory, which was introduced by Zadeh (1965) to deal with problems in which a source of vagueness is involved, has been utilized for incorporating imprecise data into the decision framework. A fuzzy set $\tilde{A}$ can be defined mathematically by a membership function $\mu_{\tilde{A}}(X)$, which assigns each element $X$ in the universe of discourse $X$ a real number in the interval $[0,1]$. A triangular fuzzy number $\tilde{A}$ can be defined by a triplet $(a, b, c)$ as illustrated in Fig 1. 


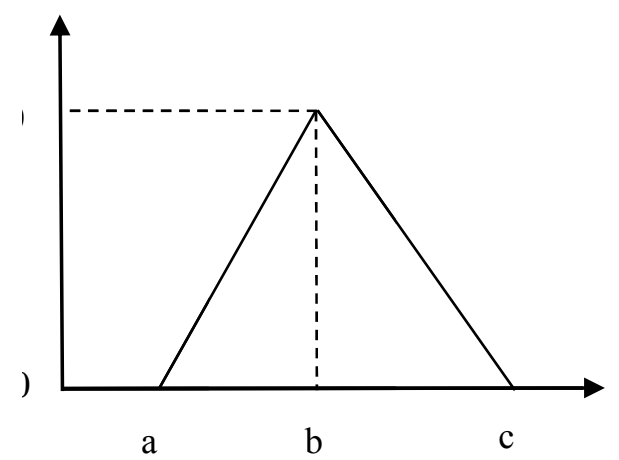

Figure 1. A triangular fuzzy number $\tilde{A}$

The membership function $\mu_{\tilde{A}}(X)$ is defined as

$$
\mu_{\tilde{A}}(x)= \begin{cases}\frac{x-a}{b-a} & a \leq x \leq b \\ \frac{x-c}{b-c} & b \leq x \leq c \\ 0 & \text { oterwise }\end{cases}
$$

Basic arithmetic operations on triangular fuzzy numbers $A_{1}=\left(a_{1}, b_{1}, c_{1}\right)$, where $a_{1} \leq b_{1} \leq c_{1}$, and $A_{2}=\left(a_{2}, b_{2}, c_{2}\right)$, where $a_{2} \leq b_{2} \leq c_{2}$, can be shown as follows:

$$
\text { Addition: } \quad \mathrm{A}_{1} \oplus \mathrm{A}_{2}=\left(\mathrm{a}_{1}+\mathrm{a}_{2}, \mathrm{~b}_{1}+\mathrm{b}_{2}, \mathrm{c}_{1}+\mathrm{c}_{2}\right)
$$

$$
\text { Subtraction: } \quad A_{1} \ominus A_{2}=\left(a_{1}-c_{2}, b_{1}-b_{2}, c_{1}-a_{2}\right)
$$

Multiplication: if $\mathrm{k}$ is a scalar

$$
\begin{aligned}
& \mathrm{K} \otimes \mathrm{A}_{1}= \begin{cases}\left(k a_{1}, k b_{1}, k c_{1}\right), & k>0 \\
\left(k c_{1}, k b_{1}, k a_{1}\right), & k<0\end{cases} \\
& \mathrm{A}_{1} \otimes \mathrm{A}_{2} \approx\left(\mathrm{a}_{1} \mathrm{a}_{2}, \mathrm{~b}_{1} \mathrm{~b}_{2}, \mathrm{c}_{1} \mathrm{c}_{2}\right), \quad \text { if } \mathrm{a}_{1} \geq 0, \mathrm{a}_{2} \geq 0 \\
& \text { Division: } \mathrm{A}_{1} \varnothing \mathrm{A}_{2} \approx\left(\frac{a_{1}}{c_{2}}, \frac{b_{1}}{b_{2}}, \frac{c_{1}}{a_{2}}\right), \quad \text { if } \quad \mathrm{a}_{1} \geq 0, \mathrm{a}_{2} \geq 0
\end{aligned}
$$

Although multiplication and division operations on triangular fuzzy numbers do not necessarily yield a triangular fuzzy number, triangular fuzzy number approximations can be used for many practical applications (Kaufmann \& Gupta, 1988). Triangular fuzzy numbers are appropriate for quantifying the vague information about most decision problems including personnel selection (e.g. rating for creativity, personality, leadership, etc.). The primary reason for using triangular fuzzy numbers can be stated as their intuitive and computational-efficient representation (Karsak, 2002). A linguistic variable is defined as a 
variable whose values are not numbers, but words or sentences in natural or artificial language. The concept of a linguistic variable appears as a useful means for providing approximate characterization of phenomena that are too complex or ill defined to be described in conventional quantitative terms (Zadeh, 1975).

\subsection{Fuzzy AHP}

Despite of its wide range of applications, the conventional AHP approach may not fully reflect a style of human thinking. One reason is that decision makers usually feel more confident to give interval judgments rather than expressing their judgments in the form of single numeric values. As a result, fuzzy AHP and its extensions are developed to solve alternative selection and justification problems. Although FAHP requires tedious computations, it is capable of capturing a human's appraisal of ambiguity when complex multi-attribute decision making problems are considered. In the literature, many FAHP methods have been proposed ever since the seminal paper by Van Laarhoven and Pedrycz (1983). In his earlier work, Saaty (1980) proposed a method to give meaning to both fuzziness in perception and fuzziness in meaning. This method measures the relativity of fuzziness by structuring the functions of a system hierarchically in a multiple attribute framework. Later on, Buckley (1985) extends Saaty's AHP method in which decision makers can express their preference using fuzzy ratios instead of crisp values. Chang (1996) developed a fuzzy extent analysis for AHP, which has similar steps as that of Saaty's crisp AHP. However, his approach is relatively easier in computation than the other fuzzy AHP approaches. In this paper, we make use of Chang's fuzzy extent analysis for AHP. Kahraman et al. (2003) applied Chang's (1996) fuzzy extent analysis in the selection of the best catering firm, facility layout and the best transportation company, respectively. Let $\mathrm{O}=\left\{\mathrm{o}_{1}, \mathrm{o}_{2}, \ldots, \mathrm{o}_{\mathrm{n}}\right\}$ be an object set, and $U=\left\{g_{1}, g_{2}, \ldots, g_{m}\right\}$ be a goal set. According to the Chang's extent analysis, each object is considered one by one, and for each object, the analysis is carried out for each of the possible goals, $g_{i}$. Therefore, $m$ extent analysis values for each object are obtained and shown as follows:

$$
\widetilde{M}_{g_{i}}^{1}, \widetilde{M}_{g_{i}}^{2}, \ldots, \widetilde{M}_{g_{i}}^{m}, \mathrm{i}=1,2, \ldots, \mathrm{n}
$$

Where $\widetilde{M}_{g_{i}}^{j}(\mathrm{j}=1,2,3, \ldots, \mathrm{m})$ are all triangular fuzzy numbers. The membership function of the triangular fuzzy number is denoted by $\mathrm{M}_{(\mathrm{x})}$. The steps of the Chang's extent analysis can be summarized as follows:

Step 1: The value of fuzzy synthetic extent with respect to the ith object is defined as:

$$
\mathrm{S}_{\mathrm{i}}=\sum_{j=1}^{m} \widetilde{M}_{g_{i}}^{j} \otimes\left[\sum_{i=1}^{n} \sum_{j=1}^{m} \widetilde{M}_{g_{i}}^{j}\right]^{-1}
$$

Where $\otimes$ denotes the extended multiplication of two fuzzy numbers. In order to obtain $\sum_{j=1}^{m} \tilde{M}_{g_{i}}^{j}$ 
We perform the addition of $\mathrm{m}$ extent analysis values for a particular matrix such that,

$$
\sum_{j=1}^{m} \widetilde{M}_{g_{i}}^{j}=\left(\sum_{j=1}^{m} l_{j}, \sum_{j=1}^{m} m_{j}, \sum_{j=1}^{m} u_{j}\right)
$$

And to obtain $\left[\sum_{i=1}^{n} \sum_{j=1}^{m} \widetilde{M}_{g_{i}}^{j}\right]^{-1}$ we perform the fuzzy addition operation of $\widetilde{M}_{g_{i}}^{j}(\mathrm{j}$ $=1,2, \ldots, \mathrm{m}) \quad$ values such that,

$$
\sum_{i=1}^{n} \sum_{j=1}^{m} \widetilde{M}_{g_{i}}^{j}=\left(\sum_{i=1}^{n} l_{i}, \sum_{i=1}^{n} m_{i}, \sum_{i=1}^{n} u_{i}\right)
$$

Then, the inverse of the vector is computed as,

$$
\left[\sum_{i=1}^{n} \sum_{j=1}^{m} \widetilde{M}_{g_{i}}^{j}\right]^{-1}=\left(\frac{1}{\sum_{i=1}^{n} u_{i}}, \frac{1}{\sum_{i=1}^{n} m_{i}}, \frac{1}{\sum_{i=1}^{n} l_{i}}\right)
$$

Where $u_{i}, m_{i}, l_{i}>0$

Finally, to obtain the $S_{j}$, we perform the following multiplication:

$$
\begin{aligned}
\mathrm{S}_{\mathrm{i}}= & \sum_{j=1}^{m} \widetilde{M}_{g_{i}}^{j} \otimes\left[\sum_{i=1}^{n} \sum_{j=1}^{m} \widetilde{M}_{g_{i}}^{j}\right]^{-1} \\
& =\left(\sum_{j=1}^{m} l_{j} \otimes \sum_{i=1}^{n} l_{i}, \sum_{j=1}^{m} m_{j} \otimes \sum_{i=1}^{n} m_{i}, \sum_{j=1}^{m} u_{j} \otimes \sum_{i=1}^{n} u_{i}\right)
\end{aligned}
$$

Step 2: The degree of possibility of $\widetilde{M}_{2}=\left(\mathrm{l}_{2}, \mathrm{~m}_{2}, \mathrm{u}_{2}\right) \geq \widetilde{M}_{1}=\left(\mathrm{l}_{1}, \mathrm{~m}_{1}, \mathrm{u}_{1}\right)$ is defined as

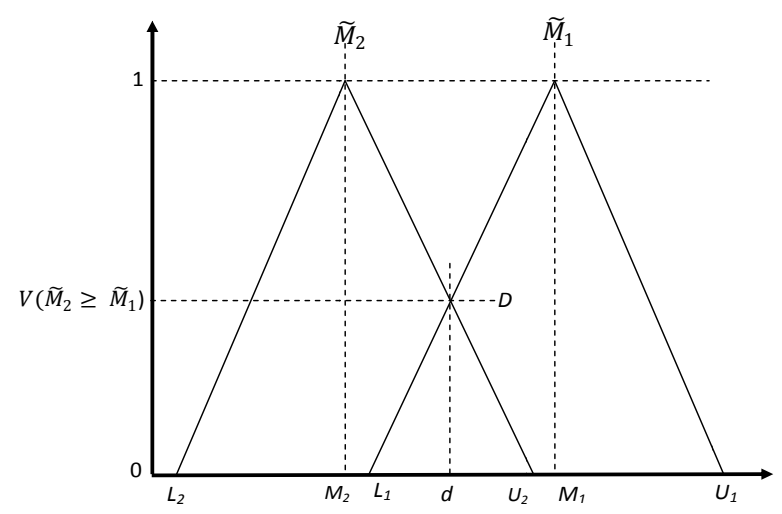

Figure 2 . The degree of possibility of $\widetilde{M}_{1} \geq \widetilde{M}_{2}$

$$
\mathrm{V}\left(\widetilde{M}_{2} \geq \widetilde{M}_{1}\right)=\sup \left[\min \left(\widetilde{M}_{1}(\mathrm{x}), \widetilde{M}_{2}(\mathrm{y})\right)\right]
$$

This can be equivalently expressed as, 


$$
\mathrm{V}\left(\widetilde{M}_{2} \geq \widetilde{M}_{1}\right)=\operatorname{hgt}\left(\widetilde{M}_{1} \cap \widetilde{M}_{2}\right)=\widetilde{M}_{2}(\mathrm{~d})=\left\{\begin{array}{cc}
1 \quad \text { if } m_{2} \geq m_{1} \\
0 \quad \text { if } l_{1} \geq u_{2} \\
\frac{l_{1}-u_{2}}{\left(m_{2}-u_{2}\right)-\left(m_{1}-l_{1}\right)}, \text { otherwise }
\end{array}\right.
$$

Fig. 2 illustrates $\quad \mathrm{V}\left(\widetilde{M}_{2} \geq \widetilde{M}_{1}\right)$ for the case $\mathrm{d}$ for the case $\mathrm{m}_{1}<\mathrm{l}_{1}<\mathrm{u}_{2}<\mathrm{m}_{1}$, where $\mathrm{d}$ is the abscissa value corresponding to the highest crossover point $\mathrm{D}$ between $\widetilde{M}_{1}$ and $\widetilde{M}_{2}$, To compare $\widetilde{M}_{1}$ and $\widetilde{M}_{2}$, we need both of the values $\mathrm{V}\left(\widetilde{M}_{1} \geq \widetilde{M}_{2}\right)$ and $\mathrm{V}\left(\widetilde{M}_{2} \geq \widetilde{M}_{1}\right)$.

Step 3: The degree of possibility for a convex fuzzy number to be greater than $\mathrm{k}$ convex fuzzy numbers $\mathrm{M}_{\mathrm{i}}(\mathrm{I}=1,2 \ldots \mathrm{K})$ is defined as

$\mathrm{V}\left(\widetilde{M} \geq \widetilde{M}_{1}, \widetilde{M}_{2}, \ldots, \widetilde{M}_{k}\right)=\min \mathrm{V}\left(\widetilde{M} \geq \widetilde{M}_{i}\right), \quad \mathrm{i}=1,2, \ldots, \mathrm{k}$

Step 4:Finally, $W=\left(\min V\left(s_{1} \geq s_{k}\right) \min V\left(s_{2} \geq s_{k}\right), \ldots, \min V\left(s_{n} \geq s_{k}\right)\right)^{T}$, is the weight vector for $\mathrm{k}=1, \ldots, \mathrm{n}$.

In order to perform a pairwise comparison among the parameters, we used the scale that is previously used in Ertuğrul et al (2008) paper. This scale is shown in Table 1.

Table 1. Linguistic variables for important of each criteria

\begin{tabular}{|l|l|}
\hline linguistic variables & $\begin{array}{l}\text { triangular fuzzy } \\
\text { numbers }\end{array}$ \\
\hline very low & $(0.00,0.00,0.00)$ \\
\hline low & $(0.10,0.20,0.30)$ \\
\hline medium low & $(0.20,0.35,0.50)$ \\
\hline medium & $(0.40,0.50,0.60)$ \\
\hline medium high & $(0.50,0.65,0.80)$ \\
\hline high & $(0.70,0.80,0.90)$ \\
\hline very high & $(0.80,1.00,1.00)$ \\
\hline
\end{tabular}

\subsection{The GTMA method}

Graph theory is a logical and systematic approach. The advanced theory of graphs and its applications are very well documented. Rao (2007) in his book presents this methodology and shows some of its applications. Graph/digraph model representations have proved to be useful for modeling and analyzing various kinds of systems and problems in numerous fields of science and technology (Darvish et al, 2009). The matrix approach is useful in analyzing the graph/digraph models expeditiously to derive the system function and index to meet the 
objectives (Rao, 2007). The graph theory and matrix methods consist of the digraph representation, the matrix representation and the permanent function representation. The digraph is the visual representation of the variables and their inter dependencies. The matrix converts the digraph into mathematical form and the permanent function is a mathematical representation that helps to determine the numerical index (Faisal, 2007).

The step by step explanation of the methodology is as follows:

Step 1. Identifying equipment selection attributes. In this step all the criteria which affect the decision is determined. This can be done by using relevant criteria available in the literature or getting information from the decision maker.

Step 2. Determine equipment alternatives. All potential alternatives are identified.

Step 3. Graph representation of the criteria and their interdependencies. Equipment selection criterion is defined as a factor that influences the selection of an alternative. The equipment selection criteria digraph models the alternative selection criteria and their inter relationship. This digraph consists of a set of nodes $\mathrm{N}=\left\{\mathrm{n}_{\mathrm{i}}\right\}$, with $\mathrm{i}=1,2, \ldots, \mathrm{M}$ and a set of directed edges $E=\left\{e_{i j}\right\}$. A node $n_{i}$ represents $i$-th alternative selection criterion and edges represent the relative importance among the criteria. The number of nodes $\mathrm{M}$ considered is equal to the number of alternative selection criteria considered. If a node ' $i$ ' has relative importance over another node ' $\mathrm{j}$ ' in the alternative selection, then a directed edge or arrow is drawn from node $\mathrm{i}$ to node $\mathrm{j}$ (i.e. $\mathrm{e}_{\mathrm{ij}}$ ). If ' $\mathrm{j}$ ' has relative importance over ' $\mathrm{i}$ ' directed edge or arrow is drawn from node $\mathrm{j}$ to node $\mathrm{i}\left(\mathrm{e}_{\mathrm{ji}}\right)(\mathrm{Rao}, 2007)$.

Step 4. Develop equipment selection criteria matrix of the graph. Matrix representation of the alternative selection criteria digraph gives one-to-one representation. A matrix called the equipment selection criteria matrix. This is an $\mathrm{M}$ in $\mathrm{M}$ matrix and considers all of the criteria (i.e. $A_{i}$ ) and their relative importance (i.e. $a_{i j}$ ). Where $A_{i}$ is the value of the $i$-th criteria represented by node $n_{i}$ and $a_{i j}$ is the relative importance of the $i$-th criteria over the $j$-th represented by the edge $e_{i j}$ (Rao, $2007 \&$ Faisal et al, 2007).

The value of $A_{i}$ should preferably be obtained from available or estimated data. When quantitative values of the criteria are available, normalized values of a criterion assigned to the alternatives are calculated by $v_{i} / v_{j}$, where $v_{i}$ is the measure of the criterion for the $i$-th alternative and $v_{j}$ is the measure of the criterion for the $j$-th alternative which has a higher measure of the criterion among the considered alternatives. This ratio is valid for beneficial criteria only. A beneficial criteria means its higher measures are more desirable for the given application. Whereas, the non-beneficial criterion is the one whose lower measures are desirable and the normalized values assigned to the alternatives are calculated $b_{\mathrm{j}} \mathrm{v}_{\mathrm{j}} / \mathrm{v}_{\mathrm{i}}$.

$$
\text { CS Matrix }=\left[\begin{array}{cccccc}
A_{1} & a_{12} & a_{13} & a & a & a_{1 . m} \\
a_{21} & A_{2} & a_{23} & \cdots & \cdots & a_{2 . m} \\
a_{31} & a_{32} & A_{3} & \cdots & \cdots & a_{3 . m} \\
\vdots & \cdots & \cdots & \cdots & \cdots & \cdots \\
\vdots & \ddots & \cdots & \cdots & \cdots & \vdots \\
a_{1} & a_{1} & a_{1} & \cdots & \cdots & A_{m}
\end{array}\right]
$$




\section{Mll Macrothink}

Journal of Management Research

ISSN 1941-899X

2012, Vol. 4, No. 3

Step 5. Obtaining alternative selection criteria function for the matrix. The permanent of this matrix, is defined as the alternative selection criteria function. The permanent of a matrix was introduced by Cauchy in 1812. At that time, while developing the theory of determinants, he also defined a certain subclass of symmetric functions which later Muir named permanents (Nourani, 1999). The permanent is a standard matrix function and is used in combinatorial mathematics (Faisal, $2007 \&$ Rao, 2006). The permanent function is obtained in a similar manner as the determinant but unlike in a determinant where a negative sign appears in the calculation, in a variable permanent function positive signs replace these negative signs (Faisal, 2007 \& Rao, 2006). Application of the permanent concept will lead to a better appreciation of selection attributes. Moreover, using this no negative sign will appear in the expression (unlike determinant of a matrix in which a negative sign can appear) and hence no information will be lost (Rao, 2006).

The per(CS) contains terms arranged in $(M+1)$ groups, and these groups represent the measures of criteria and the relative importance loops. The first group represents the measures of M criteria. The second group is absent as there is no self-loop in the digraph. The third group contains 2- criterion relative importance loops and measures of (M-2) criteria. Each term of the fourth group represents a set of a 3-criterion relative importance loop, or its pair, and measures of (M-3) criteria. The fifth group contains two sub-groups. The terms of the first sub-group is a set of two 2-criterion relative importance loops and the measures of (M-4) criteria. Each term of second sub-group is a set of a 4-attribute relative importance loop, or its pair, and the measures of (M-4) criteria. The sixth group contains two subgroups. The terms of the first sub-group are a set of a 3-criterion relative importance loop, or its pair, and 2-criterion importance loop and the measures of (M-5) criteria. Each term of the second sub-group is a set of a 5-criterion relative importance loop, or its pair, and the measures of (M-5) criteria. Similarly other terms of the equation are defined. Thus, the CS fully characterizes the considered alternative selection evaluation problem, as it contains all possible structural components of the criteria and their relative importance. It may be mentioned that this equation is nothing but the determinant of an $\mathrm{M}-\mathrm{M}$ matrix but considering all the terms as positive.

Step 6. Evaluation and ranking of the alternatives, in this step all alternatives are ranked according to their permanent values calculated in the previous step.

$$
\begin{gathered}
\operatorname{per}(\mathrm{Cs})=\prod_{\mathrm{i}=1}^{\mathrm{M}} \mathrm{A}_{\mathrm{i}}+\sum_{\mathrm{i}=1}^{\mathrm{M}-1} \sum_{\mathrm{j}=\mathrm{i}+1}^{\mathrm{M}} \ldots \sum_{\mathrm{M}=\mathrm{t}+1}^{\mathrm{M}}\left(\mathrm{a}_{\mathrm{ij}} \mathrm{a}_{\mathrm{ji}}\right) \mathrm{A}_{\mathrm{k}} \mathrm{A}_{\mathrm{l}} \mathrm{A}_{\mathrm{m}} \mathrm{A}_{\mathrm{n}} \mathrm{A}_{\mathrm{o}} \ldots \mathrm{A}_{\mathrm{t}} \mathrm{A}_{\mathrm{M}} \\
+\sum_{\mathrm{i}=1}^{\mathrm{M}-2} \sum_{\mathrm{j}=\mathrm{i}+1}^{\mathrm{M}-1} \sum_{\mathrm{k}=\mathrm{i}+1}^{\mathrm{M}} \ldots \sum_{\mathrm{M}=\mathrm{t}+!}^{\mathrm{M}}\left(\mathrm{a}_{\mathrm{ij}} \mathrm{a}_{\mathrm{jk}} \mathrm{a}_{\mathrm{ki}}+\mathrm{a}_{\mathrm{ik}} \mathrm{a}_{\mathrm{kj}} \mathrm{a}_{\mathrm{ji}}\right) \mathrm{A}_{\mathrm{l}} \mathrm{A}_{\mathrm{m}} \mathrm{A}_{\mathrm{n}} \mathrm{A}_{\mathrm{o}} \ldots \mathrm{A}_{\mathrm{t}} \mathrm{A}_{\mathrm{M}} \\
+\sum_{\mathrm{i}=1}^{\mathrm{M}-3} \sum_{\mathrm{j}=\mathrm{i}+1}^{\mathrm{M}} \sum_{\mathrm{k}=\mathrm{i}+1}^{\mathrm{M}-1} \sum_{\mathrm{l}=\mathrm{i}+2}^{\mathrm{M}} \ldots \sum_{\mathrm{M}=\mathrm{t}+1}^{\mathrm{M}}\left(\mathrm{a}_{\mathrm{ij}} \mathrm{a}_{\mathrm{ji}}+\mathrm{a}_{\mathrm{kl}} \mathrm{a}_{\mathrm{lk}}\right) \mathrm{A}_{\mathrm{m}} \mathrm{A}_{\mathrm{n}} \mathrm{A}_{\mathrm{o}} \ldots \mathrm{A}_{\mathrm{t}} \mathrm{A}_{\mathrm{M}} \\
+\sum_{\mathrm{i}=1}^{\mathrm{M}-3} \sum_{\mathrm{j}=\mathrm{i}+1}^{\mathrm{M}} \sum_{\mathrm{k}=\mathrm{i}+1}^{\mathrm{M}-1} \sum_{\mathrm{l}=\mathrm{i}+2}^{\mathrm{M}} \ldots \sum_{\mathrm{M}=\mathrm{t}+1}^{\mathrm{M}}\left(\mathrm{a}_{\mathrm{ij}} \mathrm{a}_{\mathrm{jk}} \mathrm{a}_{\mathrm{kl}} \mathrm{a}_{\mathrm{li}}+\mathrm{a}_{\mathrm{il}} \mathrm{a}_{\mathrm{lk}} \mathrm{a}_{\mathrm{kj}} \mathrm{a}_{\mathrm{ji}}\right) \mathrm{A}_{\mathrm{m}} \mathrm{A}_{\mathrm{n}} \mathrm{A}_{\mathrm{o}} \ldots \mathrm{A}_{\mathrm{t}} \mathrm{A}_{\mathrm{M}}+
\end{gathered}
$$




$$
\begin{aligned}
& \sum_{i=1}^{M-2} \sum_{j=1}^{M-1} \sum_{j=i+1}^{M} \sum_{l=1}^{M-1} \sum_{m=l+1}^{M-2} \ldots \ldots \sum_{m=t+1}^{M}\left(a_{i j} a_{j k} a_{k i}\right. \\
& \left.+a_{i k} a_{k j} a_{j i}\right)\left(a_{l m} a_{m}\right) A_{n} A_{o} \ldots A_{t} A_{m}+ \\
& \sum_{\mathrm{i}=1}^{\mathrm{M}-4} \sum_{\mathrm{j}=\mathrm{i}+1}^{\mathrm{M}-1} \sum_{\mathrm{k}=\mathrm{j}+1}^{\mathrm{M}} \sum_{\mathrm{l}=1}^{\mathrm{M}} \sum_{\mathrm{m}=\mathrm{l}+1}^{\mathrm{M}} \cdots \cdots \sum_{\mathrm{M}=\mathrm{t}+1}^{\mathrm{M}}\left(\mathrm{a}_{\mathrm{ij}} \mathrm{a}_{\mathrm{jk}} \mathrm{a}_{\mathrm{kl}} \mathrm{a}_{l m} \mathrm{a}_{\mathrm{mi}}+\right. \\
& \left.a_{i m} a_{m j} a_{l k} a_{k j} a_{j i}\right) A_{n} A_{o} \ldots . . A_{t} A_{m}+ \\
& \sum_{i=1}^{M-3} \sum_{j=i+1}^{M-1} \sum_{k=j+1}^{M} \sum_{l=1}^{M} \sum_{m=l+1}^{M-1} \sum_{n=m+1}^{M} \ldots \ldots \sum_{M=t+1}^{M}\left(a_{i j} a_{j k} a_{k i}\right. \\
& \left.+a_{i k} a_{k j} a_{j i}\right)\left(a_{l m} a_{m n} a_{n l}+a_{l n} a_{n m} a_{m l}\right) A_{o} \ldots . A_{t} A_{m} \\
& +\sum_{\mathrm{i}=1}^{\mathrm{M}-5} \sum_{\mathrm{j}=\mathrm{i}+1}^{\mathrm{M}-1} \sum_{\mathrm{k}=\mathrm{j}+1}^{\mathrm{M}} \sum_{\mathrm{l}=1}^{\mathrm{M}-2} \sum_{\mathrm{m}=\mathrm{l}+1}^{\mathrm{M}-1} \sum_{\mathrm{n}=\mathrm{m}+1}^{\mathrm{M}} \ldots \ldots \sum_{\mathrm{M}=\mathrm{t}+1}^{\mathrm{M}}\left(\mathrm{a}_{\mathrm{ij}} \mathrm{a}_{\mathrm{jk}} \mathrm{a}_{\mathrm{ki}}+\mathrm{a}_{\mathrm{ik}} \mathrm{a}_{\mathrm{kj}} \mathrm{a}_{\mathrm{ji}}\right)+ \\
& \left(a_{l m} a_{m n} a_{n l}+a_{l n} a_{n m} a_{m l}\right) A_{o} \ldots A_{t} A_{M} \\
& +\sum_{\mathrm{i}=1}^{\mathrm{M}-5} \sum_{\mathrm{j}=\mathrm{i}+1}^{\mathrm{M}-1} \sum_{\mathrm{k}=\mathrm{j}+1}^{\mathrm{M}} \sum_{\mathrm{l}=1}^{\mathrm{M}} \sum_{\mathrm{m}=\mathrm{l}+1}^{\mathrm{M}} \sum_{\mathrm{n}=\mathrm{m}+1}^{\mathrm{M}} \ldots \ldots \sum_{\mathrm{M}=\mathrm{t}+1}^{\mathrm{M}}\left(\mathrm{a}_{\mathrm{ij}}+\mathrm{a}_{\mathrm{jk}} \mathrm{a}_{\mathrm{kl}} \mathrm{a}_{\mathrm{lm}} \mathrm{a}_{\mathrm{mn}} \mathrm{a}_{\mathrm{nj}}+\right. \\
& \left.a_{i n} a_{n m} a_{m l} a_{l k} a_{k j} a_{j i}\right) A_{o} \ldots A_{t} A_{M}
\end{aligned}
$$

\section{Proposed Fuzzy AHP-Fuzzy GTMA Integrated Approach}

The integrated approach composed of Fuzzy AHP and Fuzzy GTMA methods, for location selection problem consists of 3 basic stages: (1) Data gathering, (2) FAHP computations, (3) Fuzzy GTMA computations. In the first stage, alternatives and the criteria which will be used in their evaluation are determined by experts of Tehran province Gas stations and the decision hierarchy is formed. After determining the decision hierarchy, criteria used in location selection of Gas Station are assigned weights using FAHP in the second stage. In this phase, pairwise comparison matrices are formed to determine the criteria weights. The experts make individual evaluations using the scale, provided in Table 1, to determine the values ofthe elements of pairwise comparison matrices. Computing the geometric mean of the values obtained from individualevaluations, a final pairwise comparison matrix on which there is a consensus is found. The weights of the criteria are calculated based on this final comparison matrix. In the next step of this phase, according to final comparison matrix, we obtain the weight of each criterion. Location priorities are found by using Fuzzy GTMA computations in the third stage. In fuzzy GTMA, because our decision matrix has a fuzzy number, we should calculate the crisp GTMA method for L, M and U separately. After that we obtain the fuzzy permanent matrix for any pair-wise comparison matrix. 


\section{The Application of Proposed Approach}

In this section, we demonstrate the application of the proposed method in Tehran Province Company. This Company desires to finda new location and it has ten alternatives (from $\mathrm{A}_{1}$ to $\left.A_{10}\right)$. First of all, a committee of decision-makers is formed.There are ten decision-makers in the committee. Then evaluation criteria are determined as Gain the ground for establishment of station $\left(\mathrm{C}_{1}\right)$, The distance of stations from each other $\left(\mathrm{C}_{2}\right)$, Proximity to the high pressure supply lines $\left(\mathrm{C}_{3}\right)$, Establishment of station in wide streets $\left(\mathrm{C}_{4}\right)$, Availability in crisis times $\left(\mathrm{C}_{5}\right)$ and Distance from residential areas due to noise pollution $\left(\mathrm{C}_{6}\right)$.

\subsection{Fuzzy AHP Calculations}

After forming the decision hierarchy for location selection problem, the criteria to be used in evaluation process are assigned weights by using Fuzzy AHP method. In this phase, the experts are given the task of forming individual pairwise comparison matrix by using the scale given in Table 1. Geometric means of these values are found to obtain the pairwise compassion matrix (Table 2).

Table 2. Fuzzy pair-wise comparison matrix

\begin{tabular}{|c|c|c|c|c|c|c|}
\hline & $\mathrm{C}_{1}$ & $\mathrm{C}_{2}$ & $\mathrm{C}_{3}$ & $\ldots$ & $\mathrm{C}_{5}$ & $\mathrm{C}_{6}$ \\
\hline $\mathrm{C}_{1}$ & $(1.00,1.00,1.00)$ & $(0.67,0.82,0.90)$ & $(0.60,0.77,0.87)$ & $\ldots$ & $(0.37,0.50,0.63)$ & $(0.77,0.93,0.97)$ \\
\hline $\mathrm{C}_{2}$ & $(0.87,1.26,1.56)$ & $(1.00,1.00,1.00)$ & $(0.70,0.88,0.93)$ & $\ldots$ & $(0.57,0.72,0.80)$ & $(0.73,0.87,0.93)$ \\
\hline $\mathrm{C}_{3}$ & $(1.17,1.36,1.75)$ & $(1.08,1.18,1.50)$ & $(1.00,1.00,1.00)$ & $\ldots$ & $(0.63,0.77,0.83)$ & $(0.50,0.65,0.80)$ \\
\hline $\mathrm{C}_{4}$ & $(1.07,1.17,1.37)$ & $(1.04,1.08,1.31)$ & $(1.17,1.36,1.75)$ & $\ldots$ & $(0.80,1.00,1.00)$ & $(0.73,0.87,0.93)$ \\
\hline $\mathrm{C}_{5}$ & $(1.04,1.08,1.31)$ & $(1.17,1.36,1.75)$ & $(1.26,1.42,1.73)$ & $\ldots$ & $(1.00,1.00,1.00)$ & $(0.63,0.77,0.83)$ \\
\hline $\mathrm{C}_{6}$ & $(1.04,1.08,1.31)$ & $(1.07,1.17,1.37)$ & $(1.25,1.54,2.00)$ & $\cdots$ & $(1.26,1.42,1.73)$ & $(1.00,1.00,1.00)$ \\
\hline
\end{tabular}

After forming fuzzy pair-wise comparison matrix, we calculate the weight of all criteria. The weight calculation details are given below. Because of the other calculations are similar for each comparison matrix, these are not given here and can be done simply according the computations below. The value of fuzzy synthetic extent with respect to the ith object ( $\mathrm{i}=$ $1,2, \ldots, 6)$ is calculated as

$$
\begin{aligned}
& S_{1}=(4.13,4.88,5.30) \otimes(0.0237,0.02722,0.03)=(0.097836,0.132912,0.163805) \\
& S_{2}=(4.64,5.66,6.19) \otimes(0.0237,0.02722,0.03)=(0.109759,0.154128,0.1914) \\
& S_{3}=(4.98,5.72,6.75) \otimes(0.0237,0.02722,0.03)=(0.117955,0.155733,0.20862)
\end{aligned}
$$


$\mathrm{S}_{4}=(5.81,6.48,7.36) \otimes(0.0237,0.02722,0.03)=(0.137549,0.176251,0.227531)$

$\mathrm{S}_{5}=(6.10,6.63,7.87) \otimes(0.0237,0.02722,0.03)=(0.144299,0.180334,0.243205)$

$\mathrm{S}_{6}=(6.69,7.37,8.77) \otimes(0.0237,0.02722,0.03)=(0.158457,0.200642,0.271169)$

Then the V values calculated using these vectors are shown in Table 3.

Table 3. V values result

\begin{tabular}{|l|l|l|l|l|l|l|}
\hline$(\mathrm{V})$ & $\mathrm{S}_{1}$ & $\mathrm{~S}_{2}$ & $\mathrm{~S}_{3}$ & $\mathrm{~S}_{4}$ & $\mathrm{~S}_{5}$ & $\mathrm{~S}_{6}$ \\
\hline $\mathrm{S}_{1}$ & & 0.7181 & 0.6676 & 0.3772 & 0.2914 & 0.0732 \\
\hline $\mathrm{S}_{2}$ & 1 & & 0.9786 & 0.7088 & 0.6425 & 0.4146 \\
\hline $\mathrm{S}_{3}$ & 1 & 1 & & 0.7759 & 0.7233 & 0.5276 \\
\hline $\mathrm{S}_{4}$ & 1 & 1 & 1 & & 0.95324 & 0.739 \\
\hline $\mathrm{S}_{5}$ & 1 & 1 & 1 & 1 & & 0.8067 \\
\hline $\mathrm{S}_{6}$ & 1 & 1 & 1 & 1 & 1 & \\
\hline
\end{tabular}

Thus, the weight vector from Table 3 is calculated and normalized as

$\mathrm{W}^{\mathrm{t}}=(0.020549,0.116423626,0.148163052,0.207528294,0.226526409,0.2808)$

\subsection{Fuzzy GTMA Calculations}

The weights of the criteria are calculated by Fuzzy AHP up to now, and then these values can be used in Fuzzy GTMA. After calculating the weights, we formed the fuzzy decision matrix of GTMA and after that we normalized the Fuzzy decision matrix of GTMA that shows in Table 4. 
Table 4. Decision matrix of Fuzzy GTMA

\begin{tabular}{|c|c|c|c|c|c|c|}
\hline & $\mathrm{C}_{1}$ & $\mathrm{C}_{2}$ & $\mathrm{C}_{3}$ & $\cdots$ & $\mathrm{C}_{5}$ & $\mathrm{C}_{6}$ \\
\hline $\mathrm{A}_{1}$ & $(0.28,0.43,0.55)$ & $(0.87,0.80,0.90)$ & $(0.25,0.35,0.50)$ & $\ldots$ & $(0.87,0.80,0.90)$ & $(0.50,0.50,0.60)$ \\
\hline $\mathrm{A}_{2}$ & $(0.00,0.00,0.22)$ & $(0.50,0.50,0.50)$ & $(1.00,1.00,1.00)$ & $\ldots$ & $(0.12,0.20,0.30)$ & $(0.50,0.50,0.60)$ \\
\hline $\mathrm{A}_{3}$ & $(0.57,0.62,0.66)$ & $(0.25,0.35,0.50)$ & $(0.62,0.65,0.80)$ & $\ldots$ & $(0.62,0.65,0.80)$ & $(0.00,0.00,0.20)$ \\
\hline $\mathrm{A}_{4}$ & $(0.28,0.43,0.55)$ & $(0.62,0.65,0.80)$ & $(0.12,0.20,0.30)$ & $\ldots$ & $(0.25,0.35,0.50)$ & $(0.62,0.65,0.80)$ \\
\hline $\mathrm{A}_{5}$ & $(0.14,0.25,0.33)$ & $(1.00,1.00,1.00)$ & $(0.50,0.50,0.60)$ & $\ldots$ & $(0.50,0.50,0.60)$ & $(0.00,0.00,0.20)$ \\
\hline $\mathrm{A}_{6}$ & $(0.71,0.81,0.88)$ & $(0.50,0.50,0.60)$ & $(0.87,0.80,0.90)$ & $\ldots$ & $(0.12,0.20,0.30)$ & $(0.87,0.80,0.90)$ \\
\hline $\mathrm{A}_{7}$ & $(1.00,1.00,1.00)$ & $(0.25,0.35,0.50)$ & $(0.62,0.65,0.80)$ & $\ldots$ & $(0.25,0.35,0.50)$ & $(1.00,1.00,1.00)$ \\
\hline $\mathrm{A}_{8}$ & $(0.28,0.43,0.55)$ & $(0.12,0.20,0.30)$ & $(0.00,0.00,0.20)$ & $\ldots$ & $(0.62,0.65,0.80)$ & $(0.50,0.50,0.60)$ \\
\hline $\mathrm{A}_{9}$ & $(0.57,0.62,0.66)$ & $(0.62,0.65,0.80)$ & $(0.87,0.80,0.90)$ & $\ldots$ & $(1.00,1.00,1.00)$ & $(0.00,0.00,0.20)$ \\
\hline $\mathrm{A}_{10}$ & $(1.00,1.00,1.00)$ & $(0.12,0.20,0.30)$ & $(0.87,0.80,0.90)$ & $\ldots$ & $(0.87,0.80,0.90)$ & $(0.25,0.35,0.50)$ \\
\hline
\end{tabular}

In Fuzzy GTMA method, we carry out pair-wise comparison with respect to their weight that shows in Table 5. 
Table 5. Pair-wise comparison of criteria with respect to each other

\begin{tabular}{|l|l|l|l|l|l|l|}
\hline & $\mathrm{C}_{1}$ & $\mathrm{C}_{2}$ & $\mathrm{C}_{3}$ & $\mathrm{C}_{4}$ & $\mathrm{C}_{5}$ & $\mathrm{C}_{6}$ \\
\hline $\mathrm{C}_{1}$ & & 0.150 & 0.122 & 0.090 & 0.083 & 0.068 \\
\hline $\mathrm{C}_{2}$ & 0.850 & & 0.440 & 0.359 & 0.339 & 0.293 \\
\hline $\mathrm{C}_{3}$ & 0.878 & 0.560 & & 0.417 & 0.395 & 0.345 \\
\hline $\mathrm{C}_{4}$ & 0.910 & 0.641 & 0.583 & & 0.478 & 0.425 \\
\hline $\mathrm{C}_{5}$ & 0.917 & 0.661 & 0.605 & 0.522 & & 0.447 \\
\hline $\mathrm{C}_{6}$ & 0.932 & 0.707 & 0.655 & 0.575 & 0.553 & \\
\hline $\mathrm{W}_{\mathrm{j}}$ & 0.021 & 0.116 & 0.148 & 0.208 & 0.227 & 0.281 \\
\hline
\end{tabular}

Because in Fuzzy GTMA method our decision matrix is fuzzy, we should obtain the fuzzy permanent matrix for each criterion. For example, for calculating fuzzy permanent matrix for $A_{1}$, first we should obtain the permanent matrix with the lower boundof fuzzy decision matrix as well as we should obtain the permanent matrix with the mean bound and the upper bound that show from Table 6 to Table 8 .

Table 6. Pair-wise comparison of criteria with respect to $A_{1}$ with the lower bound of fuzzy decision matrix

\begin{tabular}{|l|l|l|l|l|l|l|}
\hline $\mathrm{A}_{1}-\mathrm{L}$ & $\mathrm{C}_{1}$ & $\mathrm{C}_{2}$ & $\mathrm{C}_{3}$ & $\mathrm{C}_{4}$ & $\mathrm{C}_{5}$ & $\mathrm{C}_{6}$ \\
\hline $\mathrm{C}_{1}$ & 0.286 & 0.150 & 0.122 & 0.090 & 0.083 & 0.068 \\
\hline $\mathrm{C}_{2}$ & 0.850 & 0.875 & 0.440 & 0.359 & 0.339 & 0.293 \\
\hline $\mathrm{C}_{3}$ & 0.878 & 0.560 & 0.250 & 0.417 & 0.395 & 0.345 \\
\hline $\mathrm{C}_{4}$ & 0.910 & 0.641 & 0.583 & 0.875 & 0.478 & 0.425 \\
\hline $\mathrm{C}_{5}$ & 0.917 & 0.661 & 0.605 & 0.522 & 0.875 & 0.447 \\
\hline $\mathrm{C}_{6}$ & 0.932 & 0.707 & 0.655 & 0.575 & 0.553 & 0.500 \\
\hline
\end{tabular}




\section{Macrothink}

Table 7. Pair-wise comparison of criteria with respect to $A_{1}$ with the mean bound of fuzzy decision matrix

\begin{tabular}{|l|l|l|l|l|l|l|}
\hline $\mathrm{A}_{1}-\mathrm{M}$ & $\mathrm{C}_{1}$ & $\mathrm{C}_{2}$ & $\mathrm{C}_{3}$ & $\mathrm{C}_{4}$ & $\mathrm{C}_{5}$ & $\mathrm{C}_{6}$ \\
\hline $\mathrm{C}_{1}$ & 0.438 & 0.150 & 0.122 & 0.090 & 0.083 & 0.068 \\
\hline $\mathrm{C}_{2}$ & 0.850 & 0.800 & 0.440 & 0.359 & 0.339 & 0.293 \\
\hline $\mathrm{C}_{3}$ & 0.878 & 0.560 & 0.350 & 0.417 & 0.395 & 0.345 \\
\hline $\mathrm{C}_{4}$ & 0.910 & 0.641 & 0.583 & 0.800 & 0.478 & 0.425 \\
\hline $\mathrm{C}_{5}$ & 0.917 & 0.661 & 0.605 & 0.522 & 0.800 & 0.447 \\
\hline $\mathrm{C}_{6}$ & 0.932 & 0.707 & 0.655 & 0.575 & 0.553 & 0.500 \\
\hline
\end{tabular}

Table 8.Pair-wise comparison of criteria with respect to $A_{1}$ with the upper bound of fuzzy decision matrix

\begin{tabular}{|l|l|l|l|l|l|l|}
\hline $\mathrm{A}_{1}-\mathrm{U}$ & $\mathrm{C}_{1}$ & $\mathrm{C}_{2}$ & $\mathrm{C}_{3}$ & $\mathrm{C}_{4}$ & $\mathrm{C}_{5}$ & $\mathrm{C}_{6}$ \\
\hline $\mathrm{C}_{1}$ & 0.556 & 0.150 & 0.122 & 0.090 & 0.083 & 0.068 \\
\hline $\mathrm{C}_{2}$ & 0.850 & 0.900 & 0.440 & 0.359 & 0.339 & 0.293 \\
\hline $\mathrm{C}_{3}$ & 0.878 & 0.560 & 0.500 & 0.417 & 0.395 & 0.345 \\
\hline $\mathrm{C}_{4}$ & 0.910 & 0.641 & 0.583 & 0.900 & 0.478 & 0.425 \\
\hline $\mathrm{C}_{5}$ & 0.917 & 0.661 & 0.605 & 0.522 & 0.900 & 0.447 \\
\hline $\mathrm{C}_{6}$ & 0.932 & 0.707 & 0.655 & 0.575 & 0.553 & 0.600 \\
\hline
\end{tabular}

The permanent matrix for Table 6, Table 7 and Table 8 are 5.3081, 5.8131and 7.7297. According to this method the fuzzy permanent matrix for $A_{1}$ is $(5.3081,5.8131,7.7297)$. After that we obtain the fuzzy permanent matrix of all alternatives that shows in Table 9. 
Table 9. The fuzzy permanent matrix

\begin{tabular}{|c|c|}
\hline Alternative & Fuzzy permanent matrix \\
\hline $\mathrm{A}_{1}$ & $(5.3081,5.8131,7.7297)$ \\
\hline $\mathrm{A}_{2}$ & $(3.0829,3.1745,4.5639)$ \\
\hline $\mathrm{A}_{3}$ & $(3.3159,3.6094,5.0867)$ \\
\hline $\mathrm{A}_{4}$ & $(3.6358,4.4817,6.2481)$ \\
\hline $\mathrm{A}_{5}$ & $(3.8818,4.2848,5.4272)$ \\
\hline $\mathrm{A}_{6}$ & $(4.9421,5.1543,6.7607)$ \\
\hline $\mathrm{A}_{7}$ & $(6.5379,7.1626,8.8381)$ \\
\hline $\mathrm{A}_{8}$ & $(3.4388,3.9028,5.3625)$ \\
\hline $\mathrm{A}_{9}$ & $(5.036,5.3447,6.9629)$ \\
\hline $\mathrm{A}_{10}$ & $(6.3732,6.5581,8.0699)$ \\
\hline
\end{tabular}

In the next step, using of extent analysis method that used previously in Fuzzy AHP, we obtain the crisp permanent matrix and we rank locations based on crisp permanent matrix. Finally, we rank all Locations with respect to their permanent matrix that shows in Table 10. 
Table 10.Ranking of locations

\begin{tabular}{|c|c|c|}
\hline alternative & Crisp Permanent matrix & rank \\
\hline $\mathrm{A}_{1}$ & 0.161492 & 3 \\
\hline $\mathrm{A}_{2}$ & 0.081315 & 4 \\
\hline $\mathrm{A}_{3}$ & 0.009775 & 9 \\
\hline $\mathrm{A}_{4}$ & 0.022077 & 8 \\
\hline $\mathrm{A}_{5}$ & 0.024895 & 7 \\
\hline $\mathrm{A}_{6}$ & 0.034387 & 6 \\
\hline $\mathrm{A}_{7}$ & 0.344352 & 1 \\
\hline $\mathrm{A}_{8}$ & 0.009535 & 10 \\
\hline $\mathrm{A}_{9}$ & 0.06525 & 5 \\
\hline $\mathrm{A}_{10}$ & 0.246921 & 2 \\
\hline
\end{tabular}

According to Table $10, \mathrm{~A}_{7}$ is the best location among other locations and other locations of Gas station ranked as follow: $\mathrm{A}_{7}>\mathrm{A}_{10}>\mathrm{A}_{1}>\mathrm{A}_{2}>\mathrm{A}_{9}>\mathrm{A}_{6}>\mathrm{A}_{5}>\mathrm{A}_{4}>\mathrm{A}_{3}>\mathrm{A}_{8}$.

\section{Conclusion}

In this paper, a decision approach is provided for location selection problem. This selection problem is based on the comparisons of alternatives according to criteria. FAHP and Fuzzy GTMA compound decision making methods have been used in proposed approach. FAHP is used to assign weights to the criteria to be used in location selection, while Fuzzy GTMA is employed to determine the priorities of the alternatives. The weights obtained from FAHP are included in decision making process by using them in fuzzy GTMA computations and the alternative priorities are determined based on these weights. According to result of this paper, $\mathrm{A}_{7}$ is selected as the best location for establishing Gas Station.

\section{Acknowledgement}

The authors would like to thank the anonymous reviewers and the editor for their insightful comments and suggestions.

\section{References}

Buckley, J. J. (1985). Fuzzy hierarchical analysis. Fuzzy Sets and Systems, 17, 233-247. http://dx.doi.org/10.1016/0165-0114(85)90090-9 


\section{Macrothink}

Journal of Management Research

ISSN 1941-899X

2012, Vol. 4, No. 3

Chang, D. Y. (1996). Applications of the extent analysis method on fuzzy AHP. European Journal of Operational Research, 95, 649-655. http://dx.doi.org/10.1016/0377-2217(95)00300-2

Darvish, M., M. Yasaei, \& A. Saeedi. (2009). Application of the graph theory and matrix methods to contractor ranking. International Journal of Project Management, 27(6), 610-619. http://dx.doi.org/10.1016/j.ijproman.2008.10.004

Ertuğrul, I., \& Karakaşoğlu N. (2008). Comparison of fuzzy AHP and fuzzy TOPSIS methods for facility location selection. Int $J$ Adv Manuf Technol, 39, 783-795. http://dx.doi.org/10.1007/s00170-007-1249-8

Faisal, M.N., D. Banwet, \& R. Shankar. (2007). Quantification of risk mitigation environment of supply chains using graph theory and matrix methods. European Journal of Industrial Engineering, 1(1), 22-39. http://dx.doi.org/10.1504/EJIE.2007.012652

Kahraman, C., Cebeci, U., \& Ulukan, Z. (2003). Multi-criteria supplier selection using fuzzy AHP. Logist Inf Manag 16(6), 382-394. http://dx.doi.org/10.1108/09576050310503367

Karsak, E. E. (2002). Distance-based fuzzy MCDM approach for evaluating flexible manufacturing system alternatives. International Journal of Production Research, 40(13), 3167-3181. http://dx.doi.org/10.1080/00207540210146062

Kaufmann, A., \& Gupta, M. M. (1988). Fuzzy mathematical models in engineering and management science. Amsterdam: North-Holland.

Liang, G. S. (1999). Fuzzy MCDM based on ideal and anti-ideal concepts. European Journal of Operational Research, 112, 682-691. http://dx.doi.org/10.1016/S0377-2217(97)00410-4

Nourani, Y., \& B. Andresen. (1999). Exploration of NP-hard enumeration problems by simulated annealing--the spectrum values of permanents. Theoretical computer science, 215, (1-2), 51-68. http://dx.doi.org/10.1016/S0304-3975(99)80002-4

Rao, R. V. (2007). Decision making in the manufacturing environment: using graph theory and fuzzy multiple attribute decision making methods. Springer, London.

Rao, R. V. (2006). A decision-making framework model for evaluating flexible manufacturing systems using digraph and matrix methods. The International Journal of Advanced Manufacturing Technology, 30(11), 1101-1110. http://dx.doi.org/10.1007/s00170-005-0150-6

Saaty, T. L. (1980). The analytic hierarchy process. New York: McGraw- Hill.

Stevenson, W. J. (1993). Production / operations management. 4th ed. Richard D. Irwin Inc., Homewood.

Van Laarhoven, P. J. M., \& Pedrcyz, W. (1983). A fuzzy extension of Saaty's priority theory. Fuzzy Sets and Systems, 11, 229-241. 


\section{Macrothink

Yang, J., \& Lee, H. (1997). An AHP decision model for facility location selection. Facilities 15(9/10), 241-254. http://dx.doi.org/10.1108/02632779710178785

Zadeh, L. A. (1975). The concept of a linguistic variable and its application to approximate reasoning-I. Information Sciences, 8(3), 199-249. http://dx.doi.org/10.1016/0020-0255(75)90036-5

Zadeh, L. A. (1965). Fuzzy sets. Information and Control, 8(3), 338-353. http://dx.doi.org/10.1016/S0019-9958(65)90241-X 